\title{
INTELLIGENCE TESTING AS AN AID TO SUPERVISION
}

\author{
THEODORE SAAM \\ Superintendent of Schools, Council Bluffs, Iowa
}

In the public schools of a democracy every child must have the opportunity to develop at a rate normal to his capacity. The normal rate of progress through the school course is probably determined more largely by the intellectual capacity of a student than by any other one factor. If his intelligence can be definitely ascertained, the first step will have been taken in the proper administration of the public schools.

The method of ascertaining the intellectual ability of a child should be simple, so that the capable teachers within a school system may be able to use it successfully. It must be brief, in order to make possible the testing of every child. It must be reliable, in order that the permanent record of the child will be a correct and accurate record of his intellectual capacity. The experience of Council Bluffs with the Stanford Revision of the Binet-Simon Intelligence Test would justify the assertion that it possesses these characteristics.

In October, 1917, fourteen teachers, one from each of the elementary schools in Council Bluffs, were selected by the principals because of their general intelligence and sane judgment. By courtesy of the Extension Department of the Iowa State University, it was possible to secure the services of Dr. Sylvester, who, in a period of two weeks, explained to this group of fourteen teachers the method of determining the intelligence quotients by the use of the Terman Scale. Children were tested by him in the presence of the group, and when a sufficient familiarity with the test had been secured, each one of the group tested children under his supervision. With this limited training, these fourteen teachers have tested 2,360 children in the kindergarten, first, second, and third grades of the Council Bluffs schools during the period from December, 1917, to February, 1919 . The testing is done on Saturdays. Ten or twelve of these examiners can test eighty to one hundred children in one day. The data which follow will show, first, 
whether teachers in the elementary schools can give the tests successfully; and secondly, the value of these records in supervision.

According to Terman, the various intelligence quotients have the following significance:

\begin{tabular}{|c|c|}
\hline $\begin{array}{l}\text { Intelligence Quotients } \\
\text { Above } 140\end{array}$ & $\begin{array}{l}\text { Classification } \\
\text { Near genius }\end{array}$ \\
\hline $120-140 \ldots \ldots \ldots$ & Very superior intelligence \\
\hline $110-120 \ldots \ldots \ldots$ & Superior intelligence \\
\hline $90-110 \ldots \ldots$ & Normal or average intelligence \\
\hline $80-90 \ldots$ & Dulness \\
\hline $70-80$ & $\begin{array}{l}\text { Border line of deficiency, some- } \\
\text { times classified as dulness }\end{array}$ \\
\hline $\begin{array}{r}\text { Below } 70 \ldots \ldots \\
\quad(50-70, \text { mor } \\
(20-50, \mathrm{imb} \\
(\text { Below } 20, \mathrm{i}\end{array}$ & $\begin{array}{l}\text {. Feeble-mindedness } \\
\text { to eleven-year intelligence) } \\
\text {-to seven-year intelligence) } \\
\text {-year-old intelligence) }\end{array}$ \\
\hline
\end{tabular}

The general assumption is that the intelligence quotient remains constant. A child at five years of age with a high intelligence quotient will, in all probability, have great intellectual capacity all his life. Feeble-minded children never become normal adults.

TABLE I

Showing Comparison of the Distribution of Intelligence Quotients of 2,360 Primary Children with Terman's Scale

\begin{tabular}{|c|c|c|}
\hline $\begin{array}{l}\text { Intelligence } \\
\text { Quotients }\end{array}$ & $\begin{array}{l}905 \text { Unselected } \\
\text { Children, } 5 \text { to } \\
\text { 14 Years, Terman }\end{array}$ & $\begin{array}{l}\text { 2,360 Primary } \\
\text { Children, } \\
\text { Council Bluffs }\end{array}$ \\
\hline Below $65 \ldots .$. & Per Cent & $\begin{array}{l}\text { Per Cent } \\
\text { I. } 8\end{array}$ \\
\hline $66-75 \ldots \ldots \ldots$ & 2.3 & $4 \cdot 5$ \\
\hline $76-85 \ldots \ldots \ldots$ & 8.6 & $\begin{array}{r}4 \cdot 3 \\
10.3\end{array}$ \\
\hline $86-95 \ldots \ldots \ldots$ & 20.1 & 22.3 \\
\hline $96-105 \ldots \ldots$ & $33 \cdot 9$ & 27.0 \\
\hline $106-115 \ldots \ldots$ & 23.1 & 22.1 \\
\hline $116-125 \ldots \ldots$ & 9.0 & 8.4 \\
\hline $126-135 \ldots$ & 2.3 & 2.8 \\
\hline $136-145 \ldots \ldots \ldots$ & 0.5 & 0.8 \\
\hline
\end{tabular}

It is possible that a child with a quotient of 100 does better work than a child with a quotient of 110 because of moral characteristics. The intelligence quotient merely determines the child's mental ability. It does not ascertain the child's motive powers. 
Table I shows the distribution of the intelligence quotients of the 905 unselected children tested under Terman's supervision and the distribution of the intelligence quotients of the 2,360 primary children tested by the Council Bluffs teachers. The only striking deviation in the Council Bluffs distribution is shown in the large number of children with quotients less than 75. This can partially be explained by the fact that there is a larger percentage of subnormal children in the first three grades of school than there is in an unselected group, and, secondly, it is probable that diffidence among smaller children might also account for part of the discrepancy.

TABLE II

Showing the Distribution of Intelligence Quotients of 2,360 Primary Children of Council Bluffs Public Schools by Buildings

\begin{tabular}{|c|c|c|c|c|c|c|c|c|c|c|c|c|c|c|c|}
\hline \multirow{2}{*}{$\begin{array}{l}\text { INTELLIGENCE } \\
\text { QUOTIENTS }\end{array}$} & \multicolumn{14}{|c|}{ Building Number } & \multirow{2}{*}{$\underset{\leftarrow}{\stackrel{乛}{*}}$} \\
\hline & I & 2 & 3 & 4 & 5 & 6 & 7 & 8 & 9 & 10 & II & 12 & I3 3 & 14 & \\
\hline 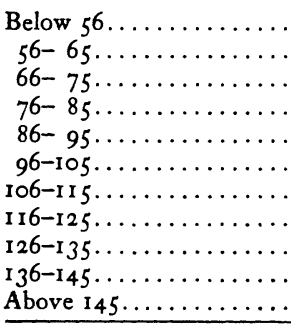 & $\begin{array}{r}1 \\
5 \\
18 \\
28 \\
62 \\
49 \\
29 \\
3 \\
0 \\
0 \\
0 \\
\end{array}$ & $\begin{array}{r}1 \\
0 \\
5 \\
20 \\
42 \\
34 \\
18 \\
9 \\
0 \\
1 \\
0 \\
\end{array}$ & $\begin{array}{r}0 \\
5 \\
13 \\
20 \\
45 \\
37 \\
36 \\
10 \\
4 \\
0 \\
0 \\
\end{array}$ & $\begin{array}{r}1 \\
5 \\
17 \\
38 \\
68 \\
72 \\
48 \\
11 \\
2 \\
0 \\
0 \\
\end{array}$ & $\begin{array}{r}1 \\
6 \\
8 \\
20 \\
36 \\
48 \\
33 \\
12 \\
1 \\
1 \\
0 \\
\end{array}$ & \begin{tabular}{r|}
1 \\
2 \\
10 \\
28 \\
50 \\
$4 \mathrm{I}$ \\
48 \\
14 \\
4 \\
0 \\
0 \\
\end{tabular} & \begin{tabular}{r|}
1 \\
1 \\
7 \\
17 \\
39 \\
60 \\
48 \\
11 \\
1 \\
1 \\
0 \\
\end{tabular} & \begin{tabular}{r|}
1 \\
0 \\
4 \\
13 \\
22 \\
29 \\
36 \\
7 \\
2 \\
2 \\
0 \\
\end{tabular} & $\begin{array}{r}0 \\
0 \\
14 \\
13 \\
36 \\
55 \\
50 \\
20 \\
9 \\
1 \\
0 \\
\end{array}$ & $\begin{array}{r}1 \\
6 \\
3 \\
18 \\
28 \\
50 \\
38 \\
24 \\
8 \\
4 \\
2 \\
\end{array}$ & $\begin{array}{r}0 \\
0 \\
2 \\
16 \\
38 \\
50 \\
45 \\
20 \\
8 \\
1 \\
0\end{array}$ & $\begin{array}{r}0 \\
0 \\
1 \\
2 \\
16 \\
25 \\
19 \\
13 \\
2 \\
0 \\
0 \\
\end{array}$ & $\begin{array}{r}2 \\
3 \\
2 \\
8 \\
36 \\
66 \\
51 \\
28 \\
16 \\
3 \\
0 \\
\end{array}$ & $\begin{array}{r}0 \\
0 \\
1 \\
2 \\
8 \\
22 \\
23 \\
17 \\
9 \\
2 \\
0 \\
\end{array}$ & $\begin{array}{r}10 \\
33 \\
105 \\
243 \\
526 \\
638 \\
522 \\
199 \\
66 \\
16 \\
2 \\
\end{array}$ \\
\hline Total. . & 195 & 130 & 170 & 262 & 166 & 198 & 186 & II 6 & 198 & 182 & 180 & 78 & 215 & 84 & 2,360 \\
\hline
\end{tabular}

Table II, which gives the distribution of the intelligence quotients of 2,360 primary children of the Council Bluffs schools by buildings, shows how unfair it is to compare the work of one school with that of another without knowing the intellectual ability of the group of children tested. This table shows that in building No. 14 the median quotient is 16 greater than it is in building No. 1, and in buildings Nos. 12 and 13 the median quotient is approximately 10 greater than it is in buildings Nos. 2 or 3 . The casual observer might suspect the difference in the intelligence of the children in these buildings from the general environment or from their personal 
appearance, but these data give an accurate rating of their intellectual ability.

In order to ascertain the relation of the quality of school work with the intelligence quotients of children, an arbitrary standard for the distribution of the quality of school work has been followed in the grading of the children of the Council Bluffs schools. The highest 10 per cent in each class are ranked as honor students; the next 30 per cent are graded $\mathrm{A}$ or strong students; the next 30 per cent, B students, medium work; and the last 30 per cent are graded $\mathrm{C}$, the poorest grade given. The 2,360 children whose quo-

TABLE III

Showing the Quality of School Work and Intelligence Quotients of 2,360 Children in Kindergarten and Primary

Grades of Council Bluffs for the Semester

Closing February 7, 1919

\begin{tabular}{|c|c|c|c|c|c|c|c|c|}
\hline \multirow{2}{*}{$\begin{array}{c}\text { Quality of } \\
\text { School } \\
\text { Work }\end{array}$} & \multicolumn{8}{|c|}{ Intelligence Quotients } \\
\hline & $56-85$ & $\begin{array}{c}\text { Per } \\
\text { Cent }\end{array}$ & $86-115$ & $\begin{array}{c}\text { Per } \\
\text { Cent }\end{array}$ & $116-145$ & $\begin{array}{c}\text { Per } \\
\text { Cent }\end{array}$ & Total & $\begin{array}{c}\text { Per } \\
\text { Cent }\end{array}$ \\
\hline H...... & 2 & 0.5 & I 44 & 9 & 67 & 24 & 213 & 9 \\
\hline A.... & 39 & 10.0 & 520 & $3 I$ & $I_{4} 6$ & $5^{\mathrm{I}}$ & 705 & 30 \\
\hline B....... & I 13 & 29.0 & $5^{84}$ & 34 & 46 & 16 & 743 & $3 I$ \\
\hline \multirow[t]{2}{*}{ C....... } & 237 & 60.5 & $43^{8}$ & 26 & 24 & 9 & 699 & 30 \\
\hline & 391 & 100.0 & 1,686 & 100 & 283 & 100 & 2,360 & 100 \\
\hline
\end{tabular}

Note. $-\mathrm{H}=$ Honor students, 10 per cent highest in class.

$A=$ Strong students, $3 \circ$ per cent of class.

$B=$ Medium students, 3 o per cent of class.

$\mathrm{C}=$ Poorest 30 per cent of class.

tients have been obtained are divided by Table III into three groups: those whose quotients fall below 85 , those whose quotients range from 86 to 115 , and those whose quotients are above 115 . An examination of this table shows that only one-half of 1 per cent of students with quotients less than 85 were honor students, whereas 24 per cent of students with quotients of over 115 were honor students. It also shows that over 60 per cent of the students with quotients below 85 did poor work, whereas only 9 per cent of students with quotients over 116 did poor work. When it is recalled that this distribution does not take cognizance of the attendance of the child, the number of times the child has repeated the grade, or the age of the child, it is very apparent that there is a very high 
correlation between the quality of school work and intelligence quotient.

TABLE IV

Showing Classification by Half-Grades and Quality of School Work of All Eight-Year-Old Children Attending

School 60 or More Days in a Semester of 87 Days Crosing February 7, I9I9

\begin{tabular}{|c|c|c|c|c|c|c|c|}
\hline \multirow{2}{*}{$\begin{array}{c}\text { Quality } \\
\text { of } \\
\text { SchооL WorK }\end{array}$} & \multicolumn{7}{|c|}{$G_{R A D E S}$} \\
\hline & $I^{1}$ & $I^{2}$ & $\mathrm{II}^{1}$ & $\mathrm{II}^{2}$ & $\mathrm{III}^{1}$ & $\mathrm{III}^{2}$ & Total \\
\hline
\end{tabular}

46 STUDENTS-INTELLIIGENCE QUOTIENTS Below 85

\begin{tabular}{r|r|r|r|r|r|r|r}
\hline $\mathrm{H} \ldots \ldots \ldots \ldots \ldots \ldots$ & $\ldots \ldots$ & $\ldots \ldots$ & $\mathrm{I}$ & $\mathrm{I}$ & $\ldots \ldots \ldots$ & $\ldots \ldots$ & 2 \\
$\mathrm{~A} \ldots \ldots \ldots \ldots \ldots \ldots$ & $\mathrm{I}$ & 3 & $\mathrm{I}$ & $\ldots \ldots$ & $\ldots \ldots$ & $\ldots \ldots$ & 5 \\
$\mathrm{~B} \ldots \ldots \ldots \ldots \ldots \ldots$ & 3 & 4 & 5 & $\ldots \ldots$ & $\ldots \ldots$ & $\ldots \ldots$ & $\mathrm{I} 2$ \\
$\mathrm{C} \ldots \ldots \ldots \ldots \ldots$ & 5 & 7 & 7 & 4 & 4 & $\ldots \ldots$ & 27 \\
\hline
\end{tabular}

5 I STUDENTS-INTELLIIGENCE QUOTIENTS ABOVE II5

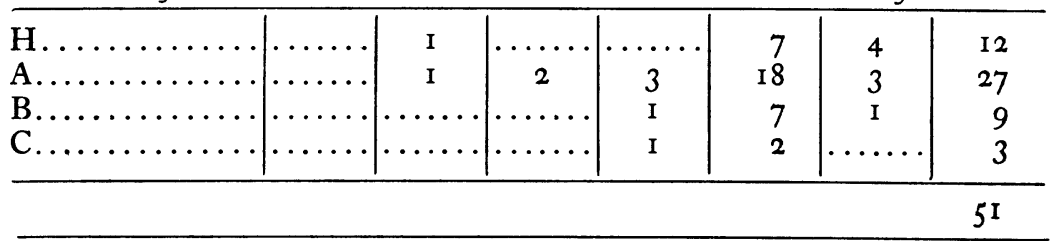

Note. $-\mathrm{H}=$ Honor students, Io per cent highest in class.

A $=$ Strong students, $3 \circ$ per cent of class.

$\mathbf{B}=$ Medium students, $3 \circ$ per cent of class.

$\mathrm{C}=$ Poorest $3 \circ$ per cent of class.

In Table IV, all eight-year-old children having quotients lower than 85 or higher than 115 who attended school 60 or more daysi $n$ a semester of 87 days closing February 7, 1919, have been classified by the grade in which they were found, the quality of work which they did, and their intelligence quotients. In other words, of all eight-year-old children in the Council Bluffs schools, 46 had quotients below 85, and 51 had quotients above 115 . The 46 eightyear-old children with quotients below 85 are largely found in Grades I and II, nearly all of them doing medium or poor work. There are four of these students who reached Grade III, but all of 
them are doing poor work. Of the 51 students whose quotients are above 115, only three did poor work. Nearly all of them were classified as honor or strong students. Most of them are in the third grade. If, then, nothing is known of an eight-year-old child attending the Council Bluffs schools except his intelligence quotient, it would be a safe statement to make that if his quotient were below 85 he would, in all probability, be found in the first or second grade doing poor work; if his quotient were over 115 , he would very probably be found in the third grade doing strong or superior work.

TABLE $V$

Showing Failures for Semester Closing February 7, igig

of I, $88_{4}$ Children in Grades I, II, and III

\begin{tabular}{r|c|c|c}
\hline $\begin{array}{c}\text { Intelligence } \\
\text { Quotients }\end{array}$ & $\begin{array}{c}\text { Number of } \\
\text { Children }\end{array}$ & $\begin{array}{c}\text { Number of } \\
\text { Failures }\end{array}$ & $\begin{array}{c}\text { Percentage of } \\
\text { Failures }\end{array}$ \\
\hline Above I I $5 \ldots \ldots \ldots$ & $2 \mathrm{I} 5$ & 7 & 3 \\
86 I I $5 \ldots \ldots \ldots \ldots$ & $\mathrm{I}, 336$ & $\mathrm{I} 72$ & $\mathrm{I} 3$ \\
Below $86 \ldots \ldots \ldots$ & 333 & $\mathrm{IO} 5$ & $3 \mathrm{I}$ \\
\hline Total......... & $\mathrm{I}, 884$ & 284 & $\mathrm{I} 5$ \\
\hline
\end{tabular}

A year ago an attempt was made to promote children from the kindergarten into the first grade on the basis of their intelligence quotients. If a child were normally well and had a mental age of six years, regardless of his physical age, he was given a trial in the first grade. In an attempt to check up the young children who were promoted into the first grade on the basis of their high quotients, an oral-reading test similar to the Gray Oral-Reading Test was given by the primary supervisor in January, 1919, to every child who had entered the first grade in September, 1918. There were 408 students tested. Of the 408,128 , or 31 per cent, were rated as superior readers in this test. Of these 408,35 had been promoted to the first grade at five years of age because they had a quotient of 115 or over. Of the 35 students with a quotient of 115 or over, 22, or 63 per cent, were rated superior. If conclusions could be drawn from this one test, it would be safe to assume that children five years old with quotients of 115 or over would do the first-grade work better than the unselected six- and seven-year-old children.

Tables V and VI show the relation between the intelligence quotients of children and the failures. It will be noted that for the 
semester closing January 25, 1918, of the 698 children in the first grade not a child with a quotient of 115 or over failed, whereas 31 per cent of those with quotients below 86 failed. For the semester closing February 7, 1919, of the 1,884 children in Grades I, II, and III whose intelligence quotients had been ascertained, 3 per cent with quotients of 115 or over failed and 31 per cent with quotients below 86 failed. When it is recalled that many of the students with quotients below 86 are repeaters, overaged, and retarded and that many times these students are promoted on the basis of time rather than of efficiency, it is probably safe to conclude that of children with quotients below 85 , one-third cannot do a year's work in a year regardless of age or regardless of the number of times the grade is repeated and that practically all children in these grades with quotients of 115 or over can do the work.

TABLE VI

Showing Failures for Semester Closing January 25, 1918 of 698 Children in Grade I

\begin{tabular}{r|c|c|c}
\hline \multicolumn{1}{c|}{$\begin{array}{c}\text { Intelligence } \\
\text { Quotients }\end{array}$} & $\begin{array}{c}\text { Number of } \\
\text { Children }\end{array}$ & $\begin{array}{c}\text { Number of } \\
\text { Failures }\end{array}$ & $\begin{array}{c}\text { Percentage of } \\
\text { Failures }\end{array}$ \\
\hline Above I I $5 \ldots \ldots \ldots$ & 58 & 0 & 0 \\
86 - I I $5 \ldots \ldots \ldots \ldots$ & 506 & 48 & 9 \\
Below $86 \ldots \ldots \ldots$ & I 34 & 42 & $3^{\mathrm{I}}$ \\
\hline Total........ & 698 & 90 & I3 \\
\hline
\end{tabular}

CONCLUSIONS

1. The Stanford Revision of the Binet-Simon Test can be given successfully by intelligent elementary teachers.

2. The intelligence quotient may be safely used in promoting children from the kindergarten to the first grade.

3. There is a high positive correlation between high intelligence quotients and strong school work.

4. There is a high positive correlation between low intelligence quotients and failures. 